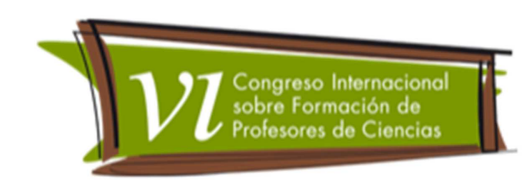

\title{
Explorando saberes populares na formação inicial de professores de química: possibilidade para a inserção da história e filosofia das ciências
}

Francisco Junior, Wilmo Ernesto'; Yamashita, Miyuki²

Categoría 2. Trabajos De Investigación En Proceso O Concluidos

\section{Resumo}

O objetivo deste trabalho foi averiguar a apropriação de elementos da história e filosofia das ciências por estudantes de licenciatura em química a partir de uma experiência que envolveu pesquisa para resgatar saberes dominados por pessoas de suas comunidades. Os licenciandos apresentaram seus resultados no formato de pôster à comunidade universitária, assim como em relatórios escritos que se constituíram no corpus do trabalho. Os relatórios demonstraram importantes indicadores do letramento científico, proporcionando uma reflexão mais ampla sobre a ciência na sociedade e sobre a presença de outros saberes que aparecem interconectados. O reconhecimento da validade social, importância histórica, cultural e econômica desses diferentes conhecimentos pode assim contribuir para a formação de professores que valorizem tais aspectos ao longo de futuras práticas.

\section{Palavras-chave}

Letramento científico; saberes populares; ensino de química.

\section{Objetivos}

A partir de uma experiência em que licenciandos em química envolveram-se numa pesquisa sobre saberes presentes em suas comunidades, o objetivo do trabalho foi estimular e avaliar a apropriação de elementos da história e filosofia das ciências por esses estudantes manifestados pela incorporação de aspectos do letramento científico em relatórios escritos.

\footnotetext{
Universidade Federal de Alagoas/UFAL, Campus Arapiraca, Brasil. E-mail: wilmojr@bol.com.br

2 Universidade Federal de Rondônia/UNIR, Brasil. E-mail: miyyama@gmail.com
} 
Revista Tecné, Episteme y Didaxis: TED. Año 2014, Número Extraordinario. ISSN Impreso: 0121-3814, ISSN web: 2323-0126 Memorias, Sexto Congreso Internacional sobre Formación de Profesores de Ciencias. 08 al 10 de octubre de 2014, Bogotá

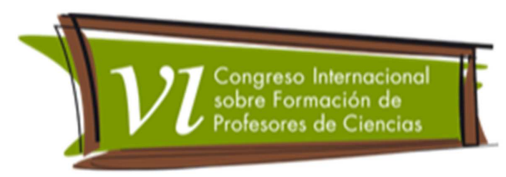

\section{Marco teórico}

A exploração dos saberes populares no contexto da educação em ciências vem sendo apontada com uma forma de valorizar o conhecimento construído por grupos sociais específicos, possibilitando adensar discussões sobre a ciência, o seu papel na sociedade, além de aspectos históricos e da preservação destes conhecimentos (Chassot, 2008). Ao trazer o conhecimento de outros coletivos para a escola, um dos objetivos é contribuir com a mudança na perspectiva das relações de dominação. Conforme assinala Arroyo (2012, pp. 11):

Esses coletivos mostram que as concepções e práticas educativas pensadas para educá-los, civilizá-los estão condicionadas pelas formas de pensá-los, ou pelo padrão de poder/saber de como foram pensados para serem subalternizados. As teorias pedagógicas não põem em prática concepções, epistemologias trazidas de fora, do centro civilizado e civilizador, mas foram gestadas na concretude de poder/saber colonizador (...).

Nesses termos, emerge a necessidade de práticas que abarquem esses outros sujeitos, na medida em que os mesmos chegam à escola com outras experiências, valores, modos de pensar e agir conforme os contextos e relações socioculturais. Isso exige a reinvenção de teorias e de práticas pedagógicas para se pensar a educação, o conhecimento e a docência (Arroyo, 2012).

Nessa perspectiva o presente trabalho analisa uma experiência que visou discutir temas da história e filosofia das ciências a partir de uma pesquisa realizada por licenciandos em química para resgatar saberes dominados por pessoas de suas comunidades. Assumindo que a História das Ciências não pode estar restrita à aprendizagem de conteúdos científicos, mas, sobretudo, pode contribuir para a reflexão acerca do desenvolvimento científico e tecnológico em interrelação com a sociedade, este trabalho é uma proposta alternativa à inserção de discussões historiográficas por meio de reflexões que privilegiem uma História das Ciências problematizadora e vinculada ao contexto sócio-cultural.

Para tanto, foram considerados na análise três aspectos: natureza da ciência (como os cientistas trabalham), linguagem científica e aspectos sociocientíficos. Tais aspectos são elementos importantes do letramento científico. Para a consideração do letramento científico, a presente pesquisa se pautou em revisão sobre a temática de Santos (2007). 
Revista Tecné, Episteme y Didaxis: TED. Año 2014, Número Extraordinario. ISSN Impreso: 0121-3814, ISSN web: 2323-0126 Memorias, Sexto Congreso Internacional sobre Formación de Profesores de Ciencias. 08 al 10 de octubre de 2014, Bogotá

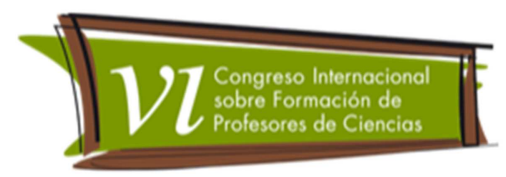

\section{Metodologia}

O trabalho caracteriza-se como uma pesquisa-ação emancipatória, entendida como "uma estratégia para o desenvolvimento de professores e pesquisadores de modo que eles possam utilizar suas pesquisas para aprimorar seu ensino e, em decorrência, o aprendizado de seus alunos" (Trip, 2005, pp. 445). A modalidade emancipatória visa "mudar o status quo não só para si mesmo e para seus companheiros mais próximos, mas de mudá-lo numa escala mais ampla, do grupo social como um todo" (Trip, 2005, pp. 458) e é assumida na medida em que a discussão dos saberes populares teve por finalidade a mudança de seu status em relação ao conhecimento científico, sobretudo por parte dos estudantes, futuros professores e que lidarão com esses diferentes conhecimentos em sala de aula. Tripp (2005) destaca ainda características da pesquisa-ação que a incluem como inovadora, contínua, proativa estrategicamente, participativa, intervencionista, problematizada, deliberada, documentada, compreendida e disseminada, além do emprego de técnicas consagradas de pesquisa para abordar a ação que se enseja melhorar a prática.

A pesquisa incluiu a participação de 31 estudantes de licenciatura em química de uma universidade federal brasileira, que cursavam disciplina sobre História da Química. No início da disciplina foi apresentada como atividade final uma pesquisa a ser desenvolvida pelos estudantes, a partir da qual deveriam identificar um saber de relevância social para a comunidade em que residiam, coletar informações a respeito desses saberes e das pessoas que o dominavam, assim como divulgar seus resultados na comunidade universitária. Os estudantes foram a campo para entrevistar a(s) pessoa(s) detentora(s) de tal saber, buscando investigar aspectos ligados à aprendizagem deste saber pela pessoa, ao seu uso social, aos aspectos econômicos, entre outros. Ao final, os resultados foram apresentados no formato de pôster à comunidade universitária. Também foram solicitados relatórios para discutir os resultados encontrados, tendo como base os elementos de história e filosofia das ciências estudados na disciplina.

Ao total foram produzidos 11 relatórios que se constituíram no corpus principal da presente pesquisa. A apreciação do material, que seguiu princípio da análise de conteúdo (Bardin, 2006), buscou captar indicadores relacionados a três aspectos: i) Compreensão da natureza da ciência; ii) Linguagem e; iii) Aspectos sociocientíficos. Os indicadores em comum foram agrupados em categorias que indicam o desenvolvimento do letramento científico pelos estudantes a partir da experiência. 
Revista Tecné, Episteme y Didaxis: TED. Año 2014, Número Extraordinario. ISSN Impreso: 0121-3814, ISSN web: 2323-0126 Memorias, Sexto Congreso Internacional sobre Formación de Profesores de Ciencias. 08 al 10 de octubre de 2014, Bogotá

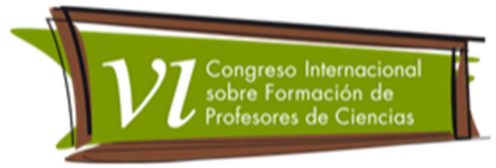

\section{Resultados e discussão}

Dos 11 relatórios analisados, em dois deles não foram observados indicadores de letramento científico. Os estudantes limitaram-se a descrever o conhecimento popular, sem se preocupar com explicações ou cotejamentos. Embora a descrição seja uma característica presente em discursos científicos, quando desacompanhada de explicações, argumentos e análise, a descrição se restringe a um conjunto de dados que carecem de interpretação.

Já os demais relatórios apresentaram ao menos um indicador em cada um dos grupos de análise considerados. No que tange ao grupo natureza da ciência, prevaleceram textos nos quais o saber popular, além de descrito, é comparado ao conhecimento científico, que por sua vez foi reconhecido como humano e social, influenciado pelos contextos históricos, mutável e com aplicações/implicações sociais (Tabela 1).

Tabela 1. Indicadores de letramento identificados sobre a compreensão da natureza da ciência.

\begin{tabular}{|l|l|l|l|l|}
\hline $\begin{array}{l}\text { Indicador de } \\
\text { letramento }\end{array}$ & $\begin{array}{l}\text { Ciência como } \\
\text { atividade } \\
\text { humana e social }\end{array}$ & $\begin{array}{l}\text { Influência do } \\
\text { contexto histórico } \\
\text { e social }\end{array}$ & $\begin{array}{l}\text { Mutabilidade do } \\
\text { saber científico }\end{array}$ & $\begin{array}{l}\text { Aplicações / } \\
\text { implicações sociais } \\
\text { da ciência }\end{array}$ \\
\hline $\begin{array}{l}\text { Relatórios } \\
\text { identificados }\end{array}$ & 8 & 7 & 7 & 7 \\
\hline
\end{tabular}

Além de contextualizar historicamente o processo de produção, a influência do meio social e o papel social, muitos textos articulam referenciais teóricos de análise.

\footnotetext{
"Ao compararmos algumas das falas da entrevistada com os textos que foram estudados (...) percebemos que o caráter social com que adquiriu o conhecimento e passa o que aprendeu para outras pessoas, coincide com a dinâmica da comunidade científica reconhecida por Kuhn onde um grupo de cientista compartilha de certa tradição de fazer ciência na sua especialidade, existindo uma noção de hierarquia, em que os membros mais velhos eram compromissados e capacitados a treinar os mais novos componentes. (...) No âmbito da pesquisa, o paradigma que movimenta essa "comunidade" composta por parentes, amigos e vizinhos, seria o conhecimento em questão: o saber fazer sabão; portanto a comunidade consiste em compartilhar esse paradigma tornando-o uma herança cultural. (...). Apesar da entrevistada não ter conhecimento cientifico de todo o processo na composição do sabão, o
} 
Revista Tecné, Episteme y Didaxis: TED. Año 2014, Número Extraordinario. ISSN Impreso: 0121-3814, ISSN web: 2323-0126 Memorias, Sexto Congreso Internacional sobre Formación de Profesores de Ciencias. 08 al 10 de octubre de 2014, Bogotá

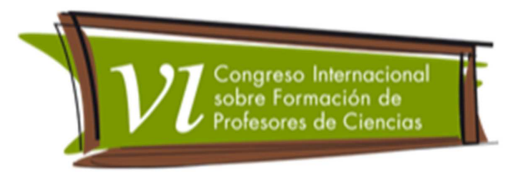

saber popular Ihe foi bastante benéfico, pois, além de estar colaborando com o meio ambiente reciclando o óleo contribui com a renda de sua família (...)."

O que se percebeu nestes textos foi a discussão das aplicações, com tessituras mais amplas com a sociedade calcada em elementos debatidos na disciplina. Boa parte ainda reconheceu a mutabilidade do conhecimento científico.

"O conhecimento cientifico (...) não é inquestionável podendo ele a qualquer momento ser contestado e perder a sua suposta veracidade, quando algum argumento contraditório conseguir sobrepor-se ao primeiro e assim sendo, não pode-se conviver com contradições. E ainda, pode ser verdade irrefutável em uma época e absurdamente errado em outra. Assim (...) esses conhecimentos geralmente vem para substituir ou aprimorar um paradigma já existente. Para que um determinado saber ou conhecimento possa ser considerado efetivamente um conhecimento cientifico, é necessário alguns fatores (...). Um deles é o aceitamento (...) por parte da comunidade cientifica."

No que tange à linguagem científica puderam ser identificados 4 indicativos de letramento científico, sendo eles a apresentação do relatório no formato de gênero científico (introdução, metodologia, resultados e discussão, conclusões e referências), emprego de terminologias e símbolos, presença de explicações e argumentação.

Tabela 2. Indicadores de letramento identificados sobre a linguagem científica.

\begin{tabular}{|l|l|l|l|l|}
\hline $\begin{array}{l}\text { Indicador de } \\
\text { letramento }\end{array}$ & $\begin{array}{l}\text { Gênero textual } \\
\text { relatório }\end{array}$ & $\begin{array}{l}\text { Termos técnicos, figuras, } \\
\text { simbolos, etc }\end{array}$ & Explicações & Argumentação \\
\hline $\begin{array}{l}\text { Relatórios } \\
\text { identificados }\end{array}$ & 5 & 6 & 6 & 6 \\
\hline
\end{tabular}

A apresentação do relatório em formato de gênero específico, apesar de ter sido solicitada, apareceu em menos da metade das produções. Uma possivel explicação para tal é a dificuldade encontrada com o próprio gênero científico, uma vez que esta foi a primeira vez que estes estudantes tiveram que produzir um texto desta natureza. $O$ uso do gênero científico, além de não ser um hábito cotidiano, exige uma reflexão consciente que depende de um processo de apropriação (Mortimer, 1999).

Não obstante essa dificuldade, conforme dados da Tabela 2, boa parte dos relatórios demonstrou o emprego de explicações e da argumentação. 
Revista Tecné, Episteme y Didaxis: TED. Año 2014, Número Extraordinario. ISSN Impreso: 0121-3814, ISSN web: 2323-0126 Memorias, Sexto Congreso Internacional sobre Formación de Profesores de Ciencias. 08 al 10 de octubre de 2014, Bogotá

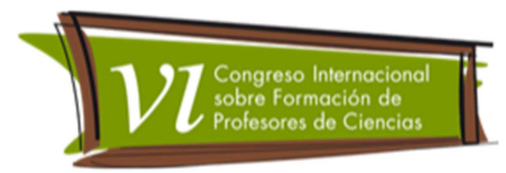

"Algo a ser destacado no pensamento de Kuhn é a influencia da comunidade científica, pois é a aceitação de um conhecimento pela comunidade que determina se um conhecimento é ou não científico. Sob este aspecto o conhecimento popular pode vir a tornar-se um conhecimento cientifico."

No trecho anterior nota-se o uso da explicação acerca do papel da comunidade científica para embasar o argumento de que, caso passe por um processo que inclui a aceitação, o saber popular pode tornar-se científico. Para Lemke (1997), aprender ciência significa se apropriar de seu discurso, o que, dentre outras coisas, inclui descrever, comparar e concluir. A presença dos indicadores de explicação e argumentação revelam indícios importantes do letramento científico.

Os aspectos sociocientíficos identificados remetem principalmente a discussão entre ciência e não ciência, o que abarcou neste caso o cotejamento do saber popular com o saber científico, a validade social do conhecimento popular e 0 reconhecimento deste como integrante da cultura local (Tabela 3).

Tabela 3. Indicadores de letramento identificados sobre aspectos sociocientíficos.

\begin{tabular}{|l|l|l|l|l|}
\hline $\begin{array}{l}\text { Indicador de } \\
\text { letramento }\end{array}$ & $\begin{array}{l}\text { Discussão ciência x } \\
\text { não ciência }\end{array}$ & $\begin{array}{l}\text { Validade } \\
\text { social }\end{array}$ & $\begin{array}{l}\text { Saber integrante da } \\
\text { cultura local }\end{array}$ & $\begin{array}{l}\text { Saber como } \\
\text { apoio ao ensino }\end{array}$ \\
\hline $\begin{array}{l}\text { Relatórios } \\
\text { identificados }\end{array}$ & 8 & 7 & 5 & 1 \\
\hline
\end{tabular}

Em um relatório também foi identificado o papel do conhecimento popular como possibilidade de ensino.

Além da argumentação sobre ciência e não ciência, destaca-se nos relatórios o reconhecimento da validade social dos saberes.

"(...) percebemos a importância do saber popular para determinado meio que o detêm, (...) é através do ensino popular que muitas culturas encontram saberes que são úteis (...) e podem ser financeiramente significantes."

Ser capaz de pensar de forma autônoma, correlacionando questões sociais e práticas são indicativos do letramento científico (Santos, 2007). Ao correlacionar a questão econômica e utilidade social do saber em sua comunidade, o estudante adquire autonomia de pensamento de sua própria experiência escolar, problematizando a questão social ali presente. 
Revista Tecné, Episteme y Didaxis: TED. Año 2014, Número Extraordinario. ISSN Impreso: 0121-3814, ISSN web: 2323-0126

Memorias, Sexto Congreso Internacional sobre Formación de Profesores de Ciencias. 08 al 10 de octubre de 2014, Bogotá

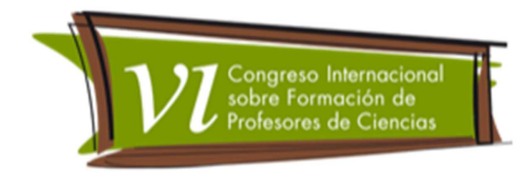

\section{Conclusōes}

A partir dos resultados é possivel inferir o desenvolvimento de indicadores do letramento científico, proporcionando uma reflexão mais ampla não somente sobre a ciência na sociedade, mas sobre a presença de outros saberes que aparecem interconectados. O reconhecimento da validade social, importância histórica, cultural e econômica desses diferentes conhecimentos pode assim contribuir para a formação de professores que valorizem tais aspectos ao longo de futuras práticas docentes, fato relevante em função das especificidades culturais em sala de aula. Caminha-se para uma mudança no que tange à compreensão social destes saberes pelos licenciandos (característica emancipatória) que, em alguns casos, reconhecem a possibilidade de seu emprego no processo educativo.

\section{Referências bibliográficas}

Arroyo, M. G. (2012). Outros sujeitos, outras pedagogias. Petrópolis: Vozes.

Bardin, L. (2006). Análise de Conteúdo. Lisboa: Ediçc̃es 70.

Chassot, A. (2008). Fazendo educação em ciências em um curso de pedagogia com inclusão de saberes populares no currículo. Química Nova na Escola, 27(s/n), 9-12.

Lemke, J. L. (1997). Aprender a hablar ciencia. Buenos Aires: Paidós.

Mortimer, E. F. (1999). Sobre chamas e cristais: a linguagem cotidiana, a linguagem científica e o ensino de ciências. In A. Chassot \& R. J. Oliveira (Orgs.), Ciência, Ética e Cultura na Educação (pp. 99-118). São Leopoldo: Editora Unisinos.

Santos, W. L. P. (2007). Educação científica na perspectiva de letramento como prática social: funções, princípios e desafios. Revista Brasileira de Educação, 12(36), 474-492.

Trip, D. (2005). Pesquisa-ação: uma introdução metodológica. Educação e Pesquisa, 37(3), 443-466. 